\title{
C-Telopeptide of Type I Collagen Generated by Matrix Metalloproteinases
}

National Cancer Institute

\section{Source}

National Cancer Institute. C-Telopeptide of Type I Collagen Generated by Matrix

Metalloproteinases. NCI Thesaurus. Code C107567.

This polypeptide is comprised of the carboxy-terminal portions of fibrillar collagen, which are joined through trivalent crosslinks and released during the degradation of mature type I collagen by matrix metalloproteinases. Increased serum concentrations of these peptides are associated with pathologies that cause bone lysis, such as multiple myeloma, osteolytic metastases, and rheumatoid arthritis. Increased blood levels of these peptides are associated with renal insufficiency. 